\title{
Identidad e iniciación cristiana (I)
}

\begin{abstract}
"Hablar de iniciación en el cristianismo es tratar de la manera por la que una persona, en un marco determinado, con un apoyo y a través de medios propios, adquiere la identidad cristiana que se interioriza verdaderamente como un don del Señor, y que implica la entrada en el misterio de Cristo y de la Iglesia"1.

"El rito de la iniciación sacramentaliza la conversión a la fe de una persona, una conversión única y difícilmente comunicable. El rito eclesializa esta conversión a la fe, tomando al converso definitivamente del ámbito privado y convirtiéndolo en una persona radicalmente pública de la Iglesia universal y local, en un fidelis, en alguien que posee ya la fuerza del Espíritu para afirmar, en la acción y en la praxis, que la Palabra se ha hecho carne"2.
\end{abstract}

Quizá en algún tiempo estuvo claro 'quién era' y 'cómo se hacía un cristiano'. Hoy las respuestas a estos dos interrogantes no son tan evidentes. Afirmar que la iniciación cristiana es el proceso para hacerse cristiano necesita seguir despejando incógnitas: ¿qué tipo de cristiano? ¿cómo articular el proceso de iniciación? El cuasi-monopolio que la Iglesia tiene sobre los rituales de transición ${ }^{3}$ complica el panorama pues se ha llegado a identificar, en la práctica, las transiciones bio-antropológicas con las transiciones teológicoexistenciales fundadas en la fe y la conversión. Ciertamente, algo está pasando desde hace años, pero ahora somos más conscientes de la problemática. La posibilidad que una persona tiene para hacerse hoy cristiana, ayudada por la estructura heredada parece que es tarea complicada debido al profundo cambio socio-cultural al que estamos sometidos.

"La situación está ante los ojos de todos. La persistencia de la sacramentalización en masa en nuestro país [...] induce a la impresión de que la praxis actual acaba por producir más indiferentes que cristianos.

1 A. CAÑIZARES Llovera, Los sacramentos de iniciación cristiana, en Teología y Catequesis 28 (1988) 632.

2 A. KAVANAGH, Los acontecimientos del ciclo vital. Los ritos civiles y el cristianismo, en Concilium 132 (1978) 181.

3 Cf. D. POWER, La odisea del hombre en Cristo, en Concilium 132 (1978) 267. 
Para muchos la primera comunión es también la última y la confirmación supone el momento de la finalización de la práctica cristiana"4.

\section{I.- LA IDENTIDAD CRISTIANA}

Si es cierto que, desde la teología cristiana, la gracia no anula la naturaleza sino que la plenifica, este axioma debe quedar claro desde el principio a la hora de afrontar el tema de la identidad cristiana. La Buena Noticia de Jesucristo no es algo extrínseco al ser humano histórico ni una mera prolongación de lo que de hecho ya estamos viviendo; el Reino es absoluta novedad en la continuidad. El paradigma de la encarnación de Calcedonia (cf. Dz 302) puede ser aplicado al tema que nos ocupa: la identidad cristiana no puede ser definida desde la confusión ni desde la separación con la identidad humana. Entre identidad humana y cristiana hay continuidad en la discontinuidad; ni plena asunción ni absoluta novedad. Si la salvación en Cristo aporta algo importante al ser humano es porque esa oferta se enraíza en lo más plenamente humano que hay en todos nosotros. Unir ambas polaridades será la tarea de la iniciación cristiana en cuanto proceso por forjar la identidad cristiana madura en medio de un mundo pluralista.

\section{1.- Aproximación a la identidad personal}

La identidad personal se adquiere dentro de una amplia red de relaciones con otros sujetos que comparten el mismo marco referencial. La identidad personal, por tanto, no es fruto de una autogeneración ${ }^{5}$ sino producto, en gran medida, de la sociedad donde tenemos nuestras raíces y en la desarrollamos nuestra existencia. No es un dato adquirido desde el nacimiento sino el logro de un largo proceso de interacción con los demás a través de acomodaciones, rupturas y asimilaciones. Por ello, hay que afirmar que la identidad personal es reflejo, en una medida importante, de la identidad grupal de la sociedad o comunidad donde el individuo nace y va creciendo como persona. Los modelos de identificación que la sociedad va proponiendo y que encarnan sus valores, van ejerciendo un poder seductivo que influirá en la orienta-

${ }^{4}$ A. LÓPEZ CALVO, La iniciación cristiana: una problemática actual, en Teología y Catequesis 72 (1999) 7. 
ción y edificación de la identidad personal. Modelos y valores sociales irán, por tanto, modelando la identidad personal de los sujetos que la componen.

El proceso de identificación con los modelos que se nos proponen es largo y muchas veces imperceptible. El individuo se va identificando con personas -reales o arquetípicas- que encarnan una serie de patrones de comportamiento y principios axiomáticos sancionados y ensalzados por la sociedad concreta. Lo que ella considera deseable lo propone como plausible y digno de ser alcanzado para que los individuos, al identificarse con tales modelos, actúen siguiendo las pautas que subyacen en el mensaje que transmiten. La identificación como proceso por el cual una persona va asimilando y haciendo suyos los patrones que una comunidad humana propone nunca se lleva a cabo plenamente.

Como hemos apuntado, en el proceso de identificación para alcanzar la propia identidad, hay personas e instituciones que sirven de mediación entre el sujeto concreto y el ideal de identidad. Los padres, maestros, estrellas del espectáculo, familia, escuela, iglesia, equipo de fútbol, himnos, historia... son todas ellas personas e instituciones mediadoras y necesarias para que cada uno de los sujetos pueda alcanzar una identidad personal con una coherencia aceptable tanto en su autocomprensión como en el ámbito social en el que vive.

La construcción de la propia identidad se hace siempre en relación con y dentro de una red social. El sentido de pertenencia a esa red es fundamental. La pertenencia de una persona a un grupo se define como un dinamismo psico-sociológico en el que el individuo entra en contacto con un grupo, se compromete e identifica en algún grado con él, participa de sus actividades, extrae de él sus motivaciones e inspira sus elecciones, preferencias y comportamientos 6 . El hecho de pertenecer a una comunidad, por tanto, nos ayuda definitivamente a encontrar nuestra propia identidad dentro de las relaciones que establecemos en ella y, al mismo tiempo, nos ayuda a entendernos como pertenecidos por los lazos de dicha sociedad. Pertenecer a una comunidad supone ser modelados por la participación en ella. Somos forjados como personas por la pertenencia a un grupo -o a varios- y, al mismo tiempo, nuestra

5 "La identidad o identificación de un individuo no puede nacer sólo de la coincidencia de ese individuo consigo mismo. Es necesario que ese individuo se sitúe también, y a la vez, en la herencia cultural recibida y desde allí se proyecte en un sentido u otro (aceptación, rechazo, modificación)." M. MATOS, La catequesis como Traditio evangelii in symbolo, en Actualidad Catequética 106 (1982) 98.

6 Cf. C. FLORISTÁN, Pertenencia a la Iglesia y catecumenado, en Phase (1971) 349, citando a $\mathrm{H}$. Carrier. 
pertenencia nos autoafirma como participantes y actores en dicho grupo 7 . El sentido de pertenencia hace que el Yo sea más que sí mismo al participar en una entidad mayor, más poderosa y rica. Participar en una identidad superior afianza y afirma la identidad endeble del Yo solitario. La pertenencia, conseguida mediante aproximaciones parciales a una comunidad, ayuda a construir la identidad personal ${ }^{8}$ y sin ella la persona no puede alcanzar su madurez y estructuración mínimas 9 .

Después de todo lo dicho, podríamos definir la identidad como aquello que permite a la persona experimentarse como una continuidad a través de los cambios, como lo que da a la persona continuidad en su carácter a lo largo del tiempo y le permite reconocerse a lo largo de las diferentes etapas de su vida y a través de las peripecias de la existencia como la misma a pesar de los cambios experimentados ${ }^{10}$. Con todo, la identidad personal no es un datum adquirido de una vez para siempre, y menos en nuestro contexto cultural, sino que es "una dimensión sumamente frágil, abierta y expuesta a riesgos. El hombre puede perder, en las revueltas de su vida cotidiana, su identidad, y aunque no llegue a perderla, jamás puede considerarla adquirida de una vez por todas. Por el contrario, es objeto de una búsqueda incesante y dura, cuya apuesta es la vida o la muerte"11.

7 Hay una referencia al significado de prosopon como 'actor' con rostro (= máscara) y al esclavo como a-prosopon.

8 Cf. C. FLORISTÁN, Pertenencia a la Iglesia y catecumenado, 349-360.

9 "La identidad personal del niño es moldeada a medida que éste ve que su conducta se refleja en los actos de quienes le rodean. Cierto grado de coherencia en las acciones de esas personas es, por ende, la condición más importante para que la identidad personal se desarrolle sin perturbaciones. Si no se cumple este requisito, aumentan las probabilidades de que se produzcan crisis de sentido subjetivas. Además, [...] las comunidades de vida necesitan un mínimo grado de coincidencia en las interpretaciones de la realidad. Sólo en estas condiciones las comunidades pueden asumir un papel de apoyo en la generación y en el mantenimiento de sentido en la vida de sus miembros. El grado de concordancia entre la comunidad de sentido que se anhela y la que se logra obtener efectivamente parece tener especial importancia. A nuestro juicio, mientras mayor sea el grado de discrepancia, aumentarán las probabilidades de que surjan crisis de sentido intersubjetivas." P. L. BERGER - T. LUCKMANN, Modernidad, pluralismo y crisis de sentido. La orientación del hombre moderno, Paidós, Barcelona 1997, 109.

10 Cf. C. FLORISTÁN, Para comprender el catecumenado, Verbo Divino, Estella 1989, 33-34 siguiendo a E.H, Erikson y J. Rof Carballo. "El tema de la identidad nos remite enseguida a la exigencia de estabilidad. De hecho, la maduración de la persona comporta la urgencia de construir identidades estables, coherentes y seguras." R. TONELLI, Retrato de un joven cristiano, en Misión Joven 268 (1999) 30.

11 P. BÜHLER, La identidad cristiana. Entre la objetividad y la subjetividad, en Concilium 216 (1988) 181. 
Para conseguir llegar a una identidad personal madura hay que partir de un sustrato fundacional: la confianza básica que ha de experimentar una persona en su relación con otras y con la misma vida, desde su más tierna infancia. La 'continuidad' que hemos mencionado hace referencia a la memoria -personal y social-y a las referencias con las que una persona se va construyendo como tal. Memoria y referencias constituyen el suelo nutricio o 'humus' donde el individuo se asienta y constituye como 'humano'. Alimentado por este humus, el individuo va madurando y llega a ser una persona adulta consiguiendo, de manera esforzada, su identidad. Por el contrario, cuanto más difuminadas sean la memoria y las referencias, tanto más frágil será la identidad personal; cuanto más firme sea ese humus, más sólida podrá ser la construcción y madurez de la identidad. En otro sentido, si las referencias y la memoria son excesivamente duras e inflexibles, la identidad personal puede o instalarse el fanatismo intransigente o bien llegar a quebrar en contraste con el entorno. $\mathrm{Si}$, por el contrario, las referencias y la memoria son excesivamente blandas, la identidad personal puede ser difícilmente alcanzable, conseguirse buscando falsas seguridades o diluirse en una identidad imprecisa.

La identidad personal se construye, está y se mantiene permanentemente entre dos polos: la continuidad y la ruptura, entre prolongar el pasado y la fractura con él, entre la identificación y la autoafirmación, entre la heteronomía y la autonomía.

"El eje de la identidad son los valores que la persona hace propios. Organizados en un sistema coherente de significado, determinan el sentido de su vida y la referencia a través de la cual los estímulos que empujan a la acción, internos y externos, son tomados, seleccionados y elaborados. Es difícil y poco practicable imaginar un control selectivo sobre los valores alrededor de los cuales construir y dar estabilidad a la propia identidad. El contexto de complejidad obstaculiza precisamente esta posibilidad.

$\mathrm{La}$ intervención formativa posible es otra. Hay que colocarla no sobre el plano 'externo', el que lanza las propuestas, sino sobre el de su adquisición. La persona está formada cuando ha llegado a construir un 'filtro' a través del cual verificar y valorar lo que acoge y lo que rechaza, de este modo, no busca mundos protegidos ni siquiera 'teme' el pluralismo de propuestas. Antes bien, las sabe acoger o rechazar a partir de algo que reconoce como determinante en la propia estructura de su personalidad.

De esa manera, la identidad misma crece y se consolida, como fruto del intercambio entre la historia personal y las aportaciones recibidas del exterior, que escriben esa misma historia.

Los valores en torno a los cuales se unifica y estabiliza la personalidad 'formada' no son elementos que se yuxtaponen unos a otros, provocando esa peligrosa desintegración de la personalidad que descubre claramente la 
ausencia de formación o la fragilidad de su realización. Al contrario, todo esto representa el punto de referencia normativo de las valoraciones y de las actuaciones cotidianas. Este filtro unificador crece y se estabiliza con el ritmo y el estilo de la vida: se consolida entre incertidumbres y nuevos comienzos, orientándose hacia una meta que está más allá de los mismos pasos más adelantados"12.

Las crisis de identidad son experiencias -espontáneas o provocadas-que una persona afronta y que, si supera con éxito, acrisolan y purifican dicha identidad. El cuidado de la identidad en estas crisis es fundamental para que puedan remontarse y así conseguir crecer y madurar como persona. En algunas edades de la vida personal -y colectiva- estas crisis son más agudas y pronunciadas ${ }^{13}$. El ejemplo más típico y estudiado es la crisis de la adolescencia. No es casualidad que, en un grandísimo número de culturas extendidas por toda la geografía, estas crisis se vivan y hasta se provoquen cuidando a las personas que las sufren por medio de complejos y elaborados sistemas rituales de iniciación, como hemos visto en el capítulo anterior. En las crisis de identidad que se resuelven de manera satisfactoria, la ruptura con el pasado y la remodelación de la identidad siempre están equilibradas. De lo contrario, la persona se puede instalar en una crisis de identidad continua o huir hacia una identidad negativa (= asunción vengativa de una identidad contraria a la que se debiera o cabría esperar conseguir) que produce desarraigo y sitúa al individuo en situación de marginalidad perpetua.

La búsqueda de la identidad es incesante y dura; entraña riesgos y dificultades. Es una aventura en las personas que quieran vivir desde la autenticidad, 'se juegan la vida', el 'ser o no ser', y por ello, esta búsqueda puede asimilarse perfectamente con el símbolo del laberinto, un tema típicamente iniciático. Los procesos y rituales de iniciación son fundamentales para que el individuo consiga una identidad personal sana y madura. Por esta razón, en muchas culturas los procesos de iniciación coinciden con la edad de la vida donde se producen las más importantes crisis de identidad. Los procesos de

12 R. TONELLI, Retrato de un joven cristiano, en Misión Joven 268 (1999) 27-28.

13 "Normalmente, en la vida de todo hombre hay un período de desarraigo natural, de confusión en su 'sí mismo', en la llamada 'crisis de identidad', en la cual es el joven 'como un artista en el trapecio que, en medio de su salto, ha de abandonar el asidero firme de su antigua situación para agarrarse a un futuro problemático y desconocido' (ERIKSON). Esta crisis puede manifestarse prematuramente, aunque también pueden presentarse problemas de identidad en la edad avanzada." J. ROF CARBALLO, Urdimbre afectiva y enfermedad. Introducción a una medicina dialógica, Labor, Barcelona 1961, 420. 
iniciación ayudan a remodelar la identidad personal en consonancia con la estructura social que inicia y a la que los individuos son iniciados.

"El término 'iniciación' indica cierto 'aprendizaje', que no es algo puramente utilitario, sino que atañe a la persona en su identidad y en su historia.

Un terreno lindante con la iniciación es el de la 'educación'. Ambas nociones poseen múltiples afinidades. Una y otra hacen referencia al ámbito de la cultura, de la humanización del hombre. Pero la educación presupone una identidad que hay que desarrollar. La iniciación parece más bien que establece esa identidad. Está de acuerdo con la estructura profunda del ser y no sólo con el desarrollo"14.

En las culturas, como la nuestra, donde los procesos iniciáticos -cuando existen- son más bien endebles o carecen de una sólida estructura comúnmente aceptada, la adolescencia, como época de crisis de identidad, se prolonga desmesuradamente, mientras que la incorporación al mundo adulto se aplaza sin desear que llegue el momento de la asunción de responsabilidades 15 .

Una cultura y unas relaciones que no ofrecen una 'confianza básica' no pueden ofrecer procesos de identidad definidos. Por el contrario, producen un sentido defectuoso de identidad que a su vez es consecuencia de una sensación de vacío, de estar perdido y sin referencias. La crisis de metarrelatos y cosmovisiones globales está en la base de muchas de las crisis de nuestra cultura.

"La situación cultural actual se caracteriza por la complejidad y el pluralismo. Esto influye notablemente en la construcción de la identidad y en su consolidación. Está surgiendo en la práctica, y con una insistente justificación también teórica, un nuevo modo de comprender y vivir la identidad. Tenemos más dudas que certezas, más signos de interrogación que de admiración. En general, no usamos palabras firmes y solemnes; preferimos expresarnos en términos relativos, inciertos y frágiles.

14 M.- L. GONDAL, Iniciación cristiana, Mensajero, Bilbao 1990, 44-45.

${ }^{15}$ Responsabilidades: los rituales de iniciación ejemplifican la estructura dialogal del ser humano. En ellos, la comunidad iniciadora y el sujeto iniciado son interlocutores de un diálogo por el que el sujeto, al responder, va constituyéose progresivamente en persona (prosopon) responsable (= que responde) y, por ello, como miembro social sujeto de derechos. "Nuestra civilización carece de los 'ritos de iniciación' que otras sociedades han empleado, en diversas épocas de la historia, para preparar la transición de la adolescencia a la edad madura. Nos hemos burlado de estos ritos considerándolos supersticiones de pueblos primitivos" J. ROF CARBALLO, Urdimbre afectiva y enfermedad, 418-419. 
Esta identidad 'débil' parece que es la apropiada para un tiempo de crisis. Alguno dice, jugando con las palabras, que ésta no es una identidad en crisis, sino la identidad necesaria para sobrevivir en una situación de crisis. Debemos encontrar cuanto antes una alternativa. Si la construcción de la identidad es el centro de la experiencia cristiana, quien descuida este elemento crucial corre el riesgo de perder lo que quiere consolidar.

La alternativa a los 'modelos fuertes' o firmes y a los débiles la ofrece la capacidad de confianza. [...La búsqueda de la identidad] se encuentra en el valor de apoyarse en un fundamento, que es sobre todo esperado, que está más allá de lo que uno puede construir y experimentar. Quien vive, se comprende y se define cotidianamente en una real experiencia de confianza, acepta la debilidad de la propia existencia como limitación infranqueable de la propia humanidad.

El fundamento esperado es la vida, progresivamente comprendida dentro del misterio de Dios: nos entregamos, nos confiamos a la vida y a su Señor. El gesto, frágil y arriesgado, de su acogida es una decisión jugada en la aventura personal totalmente orientada hacia un proyecto ya donado, que supera, juzga y orienta los inciertos pasos de la existencia.

Reconstruir personas capaces de confianza significa, por consiguiente, reconstruir un tejido de humanidad. Pero significa también echar los cimientos de la condición irrenunciable para vivir una madura experiencia cristiana.

En esto consiste realmente la vida cristiana: en un abandono en los brazos de Dios, con la actitud del niño que se fía del amor de su madre. Parece extraño: para llegar a ser adultos, descubrimos la necesidad de llegar a ser "niños""16.

\section{2. Aspectos constitutivos de la identidad cristiana ${ }^{17}$}

Podríamos aproximarnos al entendimiento de lo que es la identidad cristiana afirmando que está constituida por lı. riencia teologal cristocéntrica, suscitada por el Espíritu y que es profesadu, c'lebrada y vivida en la Iglesia como sacramento de salvación para el mundo.

La identidad cristiana parte de la experiencia del Dios-Abba, revelado plenamente en la vida, obra y misterio pascual de Jesucristo. Esta experiencia es siempre gracia y don que Dios mismo nos ofrece por medio de su Espíritu, que hemos de aceptar desde nuestra libertad. Es una experiencia teologal que se manifiesta desde y en la fe, la esperanza y la caridad.

Esta experiencia teologal no es un sentimiento vago y difuso carente de contenido. El credo no es sólo un conjunto de ideas acerca de lo que 'hay que

${ }^{16}$ R. TONELLI, Retrato de un joven cristiano, 31. 
creer' sino que también es clave hermenéutica para leer la vida, actuar en ella y esperar en la definitiva.

"La pura letra no salva nunca. Y por eso se identifica uno como cristiano en tanto cuanto la confesión de la fe del Credo pone en relación con el hecho salvífico -Cristo muerto y resucitado- que el Credo proclama. En esto consiste la redditio. [...] La catequesis salvaguarda la identidad cristiana cuando pone de manifiesto la referencia de cualquier elemento de la doctrina o praxis cristiana con el misterio cristiano, que es, en su plenitud, el misterio trinitario"18.

Al mismo tiempo, la identidad cristiana está configurada por la esperanza escatológica de un pueblo nacido del misterio de la Cruz-Resurrección de Jesucristo. Esta esperanza ya es presente, pero todavía no plenamente manifestada. Por ello, la identidad cristiana está forjada en la tensión de la espera gozosa y esperanzada del retorno del Señor. Una esperanza que, lejos de alejar los ojos de las tareas y responsabilidades históricas, más bien las ilumina con la provisionalidad del presente, sabiendo, al mismo tiempo, que ese presente está preñado del futuro de Dios. La esperanza cristiana se convierte, por tanto, en liturgia que clama “¡Marana tha!” y que vuelve a remitir necesariamente al mundo con sus conflictos y tensiones.

La identidad cristiana, para ser tal, ha de responder en la praxis de la vida concreta. La caridad cristiana es piedra angular que verifica la autenticidad de la fe y la esperanza. Lejos de todo idealismo, la identidad cristiana se va forjando en la praxis del seguimiento de Jesucristo, teniendo sus mismos sentimientos que impulsan a vivir como él (cf. Flp 2,2-11). Una vida entregada en favor de los demás, como lo hizo Jesús, es el distintivo que el cuarto evangelio marca a los que quieren ser reconocidos como los que participan de la identidad cristiana (cf. Jn 13,34-35). Una vida orientada por la caridad, confía en las promesas de Dios, tiene la esperanza de participar plenamente en su Reino y, por eso, celebra y actualiza su don -presente y futuro, otorgado y prometido al mismo tiempo- de manera auténticamente creíble en la eucaristía.

Estos tres aspectos de la identidad cristiana -fe, esperanza y caridad-son vividos por la persona en la comunidad eclesial y en comunión con ella, pues de lo contrario esa identidad se va deteriorando y erosionando hasta desapa-

17 Para un buen planteamiento del tema de la identidad cristiana cf. S. GAMARRA MAYOR, Identidad cristiana, en Nuevo diccionario de catequética I, San Pablo, Madrid 1990, 1166-1177.

18 M. MATOS, La catequesis como Traditio evangelii in symbolo, 95-107. 
recer ${ }^{19}$. La Iglesia no se puede constituir en guardiana de la identidad cristiana de sus miembros ante la 'amenaza' de una contaminación exterior, sino ámbito donde crecer y vivir dicha identidad pero siempre en referencia al mundo. Por ello, la misión es otro aspecto de la identidad cristiana ${ }^{20}$. Los que tienen una identidad cristiana madura la han de vivir en medio del mundo como sal y luz para ser sacramento de la Trinidad en los mismos gozos y esperanzas, en las mismas tristezas y angustias de los hombres de su tiempo (cf. Gaudium et Spes, 1).

De esta manera, fe, esperanza, caridad, eclesialidad y misión son las claves que pueden acercarnos a los aspectos constitutivos fundamentales de la identidad cristiana madura que sólo se pueden adquirir por medio de un proceso de iniciación.

"Los que han recibido de Dios, por medio de la Iglesia, la fe en Cristo, sean admitidos con ceremonias religiosas al catecumenado, que no es una mera exposición de dogmas y preceptos, sino una formación y noviciado convenientemente prolongado de la vida cristiana, en que los discípulos se unen con Cristo, su Maestro. Iníciense, pues, los catecúmenos convenientemente en el misterio de la salvación, en el ejercicio de las costumbres evangélicas y en los ritos sagrados que han de celebrarse en los tiempos sucesivos, y sean introducidos en la vida de fe, de liturgia y de caridad del pueblo de Dios. [...] Y como la vida de la Iglesia es apostólica, los catecúmenos han de aprender también a cooperar activamente en la evangelización y edificación de la Iglesia con el testimonio de la vida y la profesión de la fe. [...] Expóngase, por fin, claramente en el nuevo Código el estado jurídico de los catecúmenos. Porque ya están vinculados a la Iglesia, ya son de

19 Una muchedumbre de cristianos, hoy en día, se consideran "cristianos sin Iglesia" que viven un cristianismo totalmente liberado de lo institucional y que, en el seno de nuestra sociedad, pronto perderán lo que les queda de tradición cristiana. Otros cristianos parcialmente identificados con la Iglesia manifiestan una ocasión privilegiada para la reforma de actitudes y estructuras de la misma Iglesia cf. J. B. METZ, ¿Necesita la Iglesia una nueva reforma? (Una respuesta católica), en Concilium 54 (1970) 83-84; J. B. METZ, En lugar de un editorial, en Concilium 66 (1971) 319; 321-322. La indiferencia religiosa es un proceso que comienza por el abandono de unas prácticas religiosas, continúa por el deterioro de los sistemas de creencias y las escalas de valores y el alejamiento de la institución, y termina en la desafección o la indiferencia religiosa cf. J. MARTÍN VELASCO, El malestar religioso de nuestra cultura, Paulinas, Madrid 1993, 89. La comunidad cristiana debe acoger a los que han iniciado el camino de la fe para educarlos en ella y posibilitar que la puedan vivir cf. Catechesi tradendae (CT) 24. Cf. X. QUINZÁ, Los signos de un tiempo perplejo. Cómo evangelizar el nihilismo positivo de nuestra sociedad, en Sal Terrae 78 (1990) 760-763.

20 Cf. J. B. METZ, ¿Necesita la Iglesia una nueva reforma? (Una respuesta católica), 8687. "La catequesis está abierta igualmente al dinamismo misionero." CT 24. Cf. J. LÓPEZ SÁEZ, Catecumenado e inspiración catecumenal, en Nuevo diccionario de catequética I, San Pablo, Madrid 1990, 293. 
la casa de Cristo y con frecuencia ya viven una vida de fe, de esperanza y de caridad." (Ad Gentes, 14) 21.

La identidad del cristiano necesariamente estará definida en relación al seguimiento de Jesús, el Mesías, que proclama la Buena Noticia del Reino como Hijo de Dios congregando una comunidad de hermanos y vivificada por el Espíritu para ser sacramento de la acogida gratuita de Dios en medio del mundo. Esta referencia cristocéntrica de la identidad cristiana se especifica en sus aspectos constitutivos que ya hemos señalado: fe, esperanza, caridad, eclesialidad y misión. Por tanto, la iniciación cristiana ha de ser, no un absoluto, sino un proceso que haga transparente la gratuidad de Dios que llama a participar en la nueva vida que nos ofrece en Cristo dentro de una comunidad movida por su Espíritu.

"Iniciación cristiana, en resumen, es el proceso en el que, en fidelidad a la iniciativa divina, se introduce al convertido en la vida nueva del Señor resucitado, vivida, confesada, celebrada compartida y testificada en la Iglesia"22.

\section{3. Madurez en la sociedad actual y madurez en la fe}

La Ilustración trajo consigo dos cambios significativos para el cristianismo: por una parte, cae por tierra la identidad entre fe cristiana y conciencia religiosa unánimemente aceptada hasta ese momento. Por otra, se rompe la unidad, hasta ese momento considerada como evidente, entre religión y sociedad, de vida religiosa y vida social; es entonces cuando empieza un proceso en el que se considera el cristianismo, como un fragmento particular de un contexto social más amplio 23 . Estos cambios han supuesto que, en la actualidad, se perciba como algo absolutamente normal que una persona pueda ser considerada religiosa pero no necesariamente cristiana y, en caso de serlo, una cosa sean sus convicciones personales y otra su actuación pública. Como aspectos positivos, el pluralismo religioso actual ofrece un reconocimiento de la dignidad de las personas con otros credos, mientras que la autonomía de lo

${ }^{21}$ La cursiva es nuestra.

22 A. CAÑIZARES LLOVERA, Los sacramentos de iniciación cristiana, 634.

23 Cf. J. B. METZ, La fe, en la historia y la sociedad. Esbozo de una teología política fundamental para nuestro tiempo, Cristiandad, Madrid 1979, 29. Para el segundo aspecto cf. I. KANT, Respuesta a la pregunta: ¿Qué es la Ilustración?, en J. B. Erhard et al., ¿Qué es Ilustración?, Tecnos, Madrid 198922, 24. 
temporal -o la secularización- ha liberado el ámbito humano de la tutela omnipresente de la Iglesia. En su dimensión negativa, el reverso está representado por la privatización de las creencias así como la confusión y separación -para volver de nuevo al paradigma de Calcedonia- de lo que significa en la actualidad ser cristiano.

\section{a) Identidad personal burguesa ${ }^{24}$}

Lo que solemos considerar como 'persona madura' no es algo totalmente inocente y en lo que todos estamos de acuerdo. El concepto o ideal de adultez humana está cargado con el peso de una larga tradición cultural que nos condiciona. Cada pueblo, comunidad, grupo o sociedad tiene un ideal, más o menos explícito de lo que es ser una persona madura que influye tanto en los miembros como en las instituciones de dicho grupo. Nuestra sociedad occidental también tiene un concepto de lo que significa ser adulto. Dicho concepto ha sido elaborado a lo largo de muchos siglos y en él ha influido de manera decisiva la Modernidad ${ }^{25}$. En el mundo occidental de los países enriquecidos, el concepto de identidad personal es fruto de diferentes estratos. Aún a riesgo de simplificar, podemos afirmar que dicha identidad está formada por el 'matrimonio' entre el cristianismo encarnado en la cultura grecoromana y racionalidad instrumental-dominadora moderna. La identidad del hombre occidental está basada en una antropología de dominación: la persona se entiende a si misma frente a la naturaleza como sujeto dominante que la somete; su saber es una racionalidad impositiva; su práctica es dominación por medio de la transformación. El individuo occidental se entiende a sí mismo como ser dominador-sometedor. Él "es" en la medida que domina y somete: ésta es su identidad. Este principio no sólo se reduce al ámbito de la relación del hombre con la naturaleza sino que se amplía al de las relaciones sociales e interpersonales. Por tanto, la identidad del sujeto de nuestros países 'desarrollados' está construida sobre el principio de dominación ${ }^{26}$.

24 "El hombre burgués es el que se expresa en la Ilustración, es el sujeto implicado en el 'sujeto', el que se esconde bajo el hombre 'mayor de edad', 'autónomo' y 'racional' de la época moderna. El sujeto burgués es también [...] el creador de esa 'religión' que sirve -por así decir- de ornamento y escenario para las festividades de la vida burguesa, privatissime et gratis, y que desde hace mucho tiempo es la usual y corriente incluso en el cristianismo 'normal'." J. B. METZ, La fe, en la historia y la sociedad, 46.

25 Cf. I. KANT, Respuesta a la pregunta: ¿Qué es la Ilustración?

26 Cf. J. B. METZ, Más allá de la religión burguesa. Sobre el futuro del cristianismo, Sígueme, Salamanca 1982, 41. 
Del ideal de identidad personal que nos propone la sociedad actual brota el concepto de realización humana como 'carrera'. Se trata de una visión voluntarista y heroica, tanto del Yo, como de la tarea de vivir. La autorrealización descansa en los recursos propios y en las oportunidades aprovechadas. Es una concepción individualista de la existencia donde el propio éxito se opone al de los demás. Toda esta concepción de la realización como 'carrera' descansa, tanto en el presupuesto ilustrado de que el hombre es fundamento de sí mismo, como en la concepción darwiniana de que sólo los fuertes sobreviven.

\begin{abstract}
"En la actual producción social norteamericana los ciudadanos pobres se corresponderían con los montones de residuos que las fábricas vierten en sus entornos creando tasas de contaminación. Los pobres son detritus, se abandonan como stocks improductivos en las aceras, quedan quietos en las esquinas de las barriadas [...]. Están ahí como parte del sistema competitivo. El número de ricos parece gestarse a partir del número de pobres. Materialmente son un efecto de la producción, moralmente son una consecuencia que el escrutinio del mercado aplica sobre la heterogeneidad de los seres humanos. La idea de que el pobre es pobre porque es perezoso o incompetente está instalada entre muchos norteamericanos [...]"27.
\end{abstract}

\title{
a. 1. Independencia y autonomía
}

Con la Ilustración se explicitó un ideal de identidad personal basado en el concepto de 'mayoría de edad'. Ésta se entendía como la autonomía del ser humano respecto de cualquier tutela ${ }^{28}$. Las capacidades de cada individuo debían ponerse en funcionamiento para conseguir una identidad personal adulta, independiente y autónoma. Las influencias externas se consideraban perniciosas para conseguir la libertad y toda dependencia era vista como impedimento para la auténtica realización. Autonomía frente heteronomía era la clave para alcanzar esa 'mayoría de edad'. El hombre, como centro del mundo y fundamento de si mismo, se convirtió en el axioma y la medida de todas las $\operatorname{cosas}^{29}$. El problema -o la trampa, si se prefiere- es que ese 'hom-

27 V. VERDÚ, El planeta americano, Anagrama, Barcelona 19965 $64-65$.

28 Cf. J. B. METZ, La fe, en la historia y la sociedad, Cristiandad, Madrid 1979, 53-56.

29 "Una teoría universal de la emancipación sin soteriología no deja de estar sujeta a un mecanismo irracional de disculpa o de presión de la culpa. La historia de la emancipa- 
bre' abstracto no existe; sólo determinados 'hombres concretos' son centro y medida de todas las cosas, incluyendo al resto de hombres.

\section{a.2. Racionalidad}

Los argumentos fundados en la tradición y la autoridad fueron demolidos por la Ilustración. ${ }^{30}$ La autonomía suponía conducir la propia vida por la racionalidad y no por la dependencia externa. La razón se convirtió en diosa y cualquier otro modo de orientarse debía ser exorcizado. "Otras formas de acceso sensorial-intuitivo a la realidad, por ejemplo los ojos y su mirar, son recluidas en lo privado o irracional." 31 La racionalidad científica se alzó hace tiempo como el único medio válido para alcanzar la objetividad deseada.

\section{a.3. Dominación}

Este tipo de racionalidad se extendió a todos los campos del saber y del actuar (economía, política, técnica...). La racionalización ilustrada orientó la actividad humana hacia la producción y dominación de la naturaleza mediante el saber científico-técnico que, como es bien sabido, no es antropológicamente neutro. Al contrario, el encubrimiento social de la antropología de la dominación en la civilización científico-técnica ha posibilitado la mayor eficacia del sometimiento enraizado en ella. ${ }^{32}$

Esta concepción de la identidad personal, aunque común en nuestro mundo, tiene muchos inconvenientes: afirmación de la primacía de los fuertes, productivos y dominadores; 33 legitimación del machismo explícito o encu-

ción sin la historia de la redención somete al sujeto histórico, a la vista de la historia concreta del sufrimiento, a nuevas coacciones irracionales [...]. Negarse a asumir la culpa no es promover una forma de libertad concreta, sino una mal disimulada heteronomía. La autonomía y mayoría de edad de la emancipación total está llena de contradicciones internas. Se basa en la suspensión parcial o total de la identidad del sujeto activo, y al final esa autonomía y mayoría de edad, cuando vive de la represión de la culpa o a costa de los sujetos de 'coartada' y, por lo mismo, no siente anhelo de redención y reconciliación, viene a ser lo que Adorno, lleno de clarividencia, temía: trivial. Expresión de una libertad abstracta, a medias. ¡Historia final de la libertad como apoteosis de la trivialidad!” J. B. METZ, La fe, en la historia y la sociedad, 138-139.

30 Cf. J. B. METZ, La fe, en la historia y la sociedad, 49-51.

31 J. B. METZ, Más allá de la religión burguesa, 41.

32 Cf. J. B. METZ, Más allá de la religión burguesa, 42.

33 [...] "el lenguaje de la Ilustración no debe hacernos perder de vista que él mismo, en definitiva, sirvió para erigir al burgués propietario en sujeto de la razón política. La 
bierto; olvido de las pasividades y derrotados de la existencia34; exclusión de la mayor parte de la humanidad; degradación personal y ecológica... ${ }^{35}$

\section{b) Identidad personal cristiana}

La iniciación cristiana que pretenda ser tal ha de ser el proceso empeñado en favorecer la creación de una nueva identidad en la persona: la identidad cristiana. La iniciación cristiana en los países occidentales de tradición católica y herederos de la Ilustración ha de tener, como punto de partida, la identidad que posee su destinatario (antropología del sometimiento), para introducirlo en la nueva identidad cristiana cuyo culmen es celebrado en la eucaristía como memoria passionis. Son dos identidades radicalmente diferentes, a pesar de que la religión burguesa intente identificarlas.

mayoría de edad que proclamaba la Ilustración no se entendía como mayoría de edad para los que nada poseían, para la población rural, para los campesinos, que en la época en que se escribieron las enciclopedias eran casi todos analfabetos. Así, en la crítica de la razón metafísica, con esas enfáticas expresiones de 'mayoría de edad' y 'sujeto', lo que se afirma es una nueva élite, una nueva aristocracia, es decir, en imagen invertida, lo mismo que se combatía." J. B. METZ, La fe, en la historia y la sociedad, 57.

34 "'Los pobres deben sentirse avergonzados de su dependencia', escribía Robert Malthus en su Ensayo sobre la población de 1789, y Dole y Gingrich deciaraban lo mismo respecto a legiones de desarrapados que ambulaban a la espera del cheque gubernamental. Desean que la mayor parte se rediman por sí solos a través del esfuerzo personal y la fe en el sueño americano. Sólo cuando sus lesiones físicas o mentales irreversibles les impidan de verdad la liza serán merecedores de limosna. En su opinión, el Estado haría mal si contribuyera con sus fondos a proteger la indolencia de los que se califican de míseros." V. VERDÚ, El planeta americano, 42-43.

35 "El saber científico de la Edad Moderna ha recibido su impronta del saber dominador de la naturaleza; la comprensión antropológica que el hombre tiene dentro de este saber es la de un sujeto que domina la naturaleza. Scientia et potentia in idem coincidunt: esta frase de Bacon caracteriza el saber científico moderno como un saber dominador. Por consiguiente, en una sociedad totalmente influida por este saber científico, cualquier otra forma de relación o de saber humano -como, por ejemplo, el sufrimiento, el dolor, la tristeza, y también la alegría, el juego, etc.- tiene una validez puramente funcional y derivada y su rango cognitivo crítico es notablemente subestimado. [...] Nuestra representación de la historia está también unilateralmente caracterizada por una ceguera para comprender el rango del sufrimiento. Para nosotros, la historia se define, consciente o inconscientemente, como una historia de los que han conseguido abrirse camino, de los que han tenido éxito, de los vencedores. En el terreno de la historia está vigente una especie de darwinismo, según el cual se admite el principio de la selección, que se plasmaría en el Vae victis!" J. B. METZ, El futuro a la luz del memorial de la pasión. Una forma actual de la responsabilidad del creyente, en Concilium 76 (1972) 324-325. 
"Si no ando desencaminado, la crítica de Kierkegaard a la 'cristiandad' podría entenderse ya como una primera forma de crítica a la religión burguesa dentro del cristianismo. Según él, en efecto, la 'cristiandad' -sin causar gran sensación ni darse cuenta ella misma- ha identificado la existencia cristiana más o menos con la existencia 'natural' del burgués; subrepticiamente la praxis cristiana del seguimiento se ha transformado en praxis burguesa. Bajo la forma de 'cristiandad', el cristianismo ha vuelto a,conciliarse con gran éxito y poco menos que triunfantemente con el poder de la sociedad dominante, esto es, con la sociedad burguesa. Pero ¿a qué precio? Al precio, opina Kierkegaard, de acabar con el propio cristianismo, con el cristianismo del seguimiento, como él subraya una y otra vez"36.

La identidad cristiana tiene su referente normativo en la experiencia de Cristo. Él es el que definirá, no de manera categorial, sino desde su seguimiento lo que significa ser cristiano. Esta identidad es, al mismo tiempo, don de Dios y acogida por parte humana. Tradicionalmente se ha resumido la experiencia cristiana como un todo complejo en las llamadas 'virtudes teologales'.

36 J. B. METZ, ¿Religión mesiánica o burguesa? Sobre la crisis de la Iglesia en la República Federal Alemana, en Concilium 145 (1979) 251. Después de los primeros envites de la modernidad, Kierkegard reacciona con una crítica a la clásica identidad cristiana, tal como se estaba viviendo en la Dinamarca del siglo XIX . No creemos que esta crítica deba pasar desapercibida en nuestro estudio ya que, de modo indirecto, sigue en boca de muchos de nuestros contemporáneos y, de modo directo, ya hemos hecho referencia a parte de ella aludiendo a la crítica que Metz hace de la identidad cristiana burguesa. Su crítica se centra en tres referencias objetivas de identificación cristiana. $1^{\text {a) }}$ Pertenencia eclesial como pertenencia nacional: Nuestro autor critica la equivalencia establecida entre pertenencia nacional, pertenencia eclesial e identidad cristiana. Durante siglos -quizá el origen más remoto habría que situarlo en el edicto de Teodosio- se ha considerado que el ser miembro de una sociedad tradicionalmente cristiana implica necesariamente pertenecer a la Iglesia y, por descontado, ser obligatoriamente cristiano. Estas equivalencias lo que hacen, en definitiva, es considerar que un cristiano no se hace, sino que nace como tal al ser engendrado en un contexto socio-nacional cristiano. La crítica que Kierkegaard hace de este presupuesto es que el cristianismo se degrada y diluye cuando se es cristiano 'por nacimiento'. El estado de cristiandad lo penetra todo, de tal manera que, el mismo cristianismo, al diluirse, se pierde. $2^{\mathrm{a})}$ Adhesión intelectual a la fe: El idealismo alemán de Hegel convirtió la fe cristiana en un 'objeto de saber'. Contra esta tendencia reaccionó Kierkegaard aduciendo que en el cristianismo hay que distinguir entre doctrina y su mensaje existencial. Por ello, afirma que en materia de fe lo importante no es la adhesión intelectual sino la apropiación existencial de la misma. $3^{\mathrm{a}}$ ) Moralización de la fe: El pensador danés rechaza igualmente la moralización de la fe cristiana. Insiste en que lo religioso, al insertarse en el ámbito de lo existencial, debe estar articulado con la dimensión ética pero no directamente sino pasando a través de un rodeo: mediante la apropiación existencial. La pasión existencial, de esta manera, transciende las tareas éticas y en ocasiones llega a la superación de la misma ética (cf. la figura de Abrahán en Temor y temblor). Esto no significa que se suspenda la actuación ética sino que la reorienta. 
Desde la identidad cristiana, la realización personal se concibe como 'vocación', es decir, como respuesta de la persona a la llamada gratuita por parte de Dios. La vida es, al mismo tiempo, don y tarea. La existencia humana es saber que lo que somos se nos ha dado gratuitamente por amor y, por amor, hemos de ofrecerlo gratis. La realización personal, así entendida, no es tanto una conquista autosuficiente y competitiva sino que descansa en la certeza liberadora de que podemos responder porque, previamente, ya se nos ha dado esa capacidad. Los propios límites y fracasos no frustran sino que pueden ser reconocidos porque hemos sido aceptados previamente por el amor incondicional de Dios, porque la Gracia nos precede. El tiempo no es un enemigo que nos devora - kronos- sino el lugar de la gracia, con una densidad inesperada -kairos-, donde el mismo Dios nos sale al encuentro.

Entender la vida como vocación ayuda a forjar una identidad personal que, lejos de encerrarse en el individualismo de la competición, nos abre a entender nuestra realización en función del crecimiento de todo el Cuerpo del que formamos parte ${ }^{37}$. Lejos de ser la hazaña solitaria del héroe prometeico, la vida se convierte en participación en una obra comunitaria ( cf. 1 Cor 12-14; Ef 4,13-16). La memoria del Evangelio es necesaria para poder celebrar y vivir auténticamente la fe. La eucaristía remite al significado profundo de la nueva identidad que Jesús propone a los suyos: una identidad forjada en la entrega y servicio hasta el final, como Él mismo hizo (cf. Mc 9,30-37; 10,3245; Jn 13,2-17). La eucaristía -meta de la iniciación cristiana-concentra en sí una nueva identidad, diferente a la burguesa, pues une en sí mística y política, sin separación ni dicotomía. Vivir a costa de otros, sometiéndolos y dominándoles, supone desgarrar el mantel de la mesa eucarística; al mismo tiempo, sentarse juntos alrededor del mismo altar debe suponer una praxis social y política en favor de una mesa de la que nadie quede excluido ${ }^{38}$.

37 Hay un "peligro social que amenaza la identidad a escala mundial: la imperceptible desaparición del hombre como sujeto, la muerte del individuo bajo las anónimas presiones y estructuras de un mundo construido por una fría racionalidad, que, por tanto, propaga la fatiga de la identidad, la pérdida del recuerdo y la inconsistencia del alma. Para vencer estos peligros se hace necesaria la creación de identidades que no estén configuradas simplemente según los modelos tradicionales de identidad colectiva. ¿Representa la Iglesia, frente a tales necesidades y conflictos, una simple promesa impotente? ¿O sería posible que, al final, la Iglesia como Iglesia universal y la Iglesia universal como Iglesia del pueblo nuevo se convirtiera en modelo impulsor de tal identidad? Pero adviértase que se trata sólo de una visión. ¿Sólo de una visión?" J. B. METZ, La fe, en la historia y la sociedad, 162-163.

$38 \mathrm{Cf}$. J. SASTRE, Algunas claves para una pastoral renovada del sacramento de la confirmación, en Teología y Catequesis 74 (2000) 63-66. 


\section{b.1. Interdependencia: fe}

A pesar de toda la ideología ilustrada, el ser humano no va evolucionando de manera lineal y ascendente desde una dependencia y heteronomía infantil hasta una independencia y autonomía adulta. La persona, por ser tal, se hace, crece y madura en una red de interdependencias no sólo necesarias sino también deseables. La autosuficiencia es una ilusión que termina por destrozar a la persona. La confianza básica en otros y en el Otro no es una merma de la identidad personal madura sino que la posibilita.

"La historia de la religión bíblica narra cómo va haciéndose sujeto un pueblo, y el individuo dentro de él, en la presencia de su Dios. 'Sujeto', en este contexto, no es el individuo aislado, la mónada, que sólo en un tiempo ulterior se percató de su coexistencia con otros sujetos. Las experiencias de solidaridad y antagonismo, de liberación y angustia, compartidas con otros sujetos pertenecen por principio a la constitución del sujeto religioso, con lo que preguntarse por la relación del sujeto individual con los demás resulta aquí una cuestión más bien presuntuosa, producto de una abstracción tardía. [...] La idea bíblico-cristiana de Dios es [...] una idea esencialmente práctica. Como tal no es expresión de un avasallamiento a posteriori del sujeto y de su preconcebida identidad por medio de fuerzas misteriosas [...]. No es en absoluto una superestructura que adviene a la identidad ya formada del sujeto, sino una idea forjadora de identidad, que incide en la base misma de la existencia. Una idea que se opone a la formación de una identidad del sujeto centrada en el tener y el poseer y que hace del sujeto un sujeto solidario"39.

La fe cristiana es, sobre todo, la adhesión, no a un cuerpo doctrinal, sino a la persona de Jesús, a su mensaje, su práctica y su causa -el Reino-, a su vida, muerte y resurrección. La fe tiene un enraizamiento antropológico, un referente religioso y una dimensión ética: la fe radica en el interior de la persona religiosa, no en las instituciones religiosas; se mueve en el mundo del misterio, no en el de la magia o la superstición; y activa las estructuras profundas del creyente para no quedar recluida en la intimidad ni en el mundo de lo sagrado sino que se explicita en el espacio público y en el ámbito de lo profano. Por eso, la fe implica a la totalidad de la persona y de la realidad. La fe en Jesucristo es una fe totalizante que conduce al cristiano a hacerse cargo de la realidad para transformarla desde los valores del Reino ${ }^{40}$.

El sujeto de la fe cristiana no es el yo singular en cuanto individuo aislado sino el yo-persona en su condición de hermano. La opción personal de fe

39 J. B. METZ, La fe, en la historia y la sociedad, 77-78. 
tiene lugar "como amoroso acogerse en la fe más grande de los otros, de la comunidad, de la 'Iglesia' y su 'Subjetividad'. De esta forma la fe del individuo echa sus raíces, en cierto sentido, en una auténtica transubjetividad de una fe más grande. Naturalmente, el sujeto no puede abandonarse a ese suelo firme del que se alimenta su fe y sin comprometerse personalmente, sino que debe hacer suyo ese suelo por la apertura amante de la existencia hacia los otros, en una lucha nunca terminada contra la otra alternativa de su existencia, contra el cerrarse al hermano y a la comunidad" 41 .

\section{b.2. Receptividad: esperanza}

El ser humano no se construye desde la sola racionalidad autónoma sino desde la receptividad de otras instancias dadoras de sentido. Cada persona no es la primera en aparecer en la escena del mundo. La tradición, de la que uno es deudor, hace que el individuo sea acogido y, al mismo tiempo, pueda acoger a los otros. Las relaciones interpersonales no se reducen a mero cálculo racional sino que se basan sobre todo en la gratuidad. El sustrato que nos mantiene propicia en nosotros una apertura esperanzada hacia el futuro, más allá de todo cálculo de probabilidades. Por todo ello, la esperanza cristiana se basa en la acogida que el mismo Dios nos brinda y que nos llama a todos "a ser sujetos en su presencia." 42 Para E. Bloch, la esperanza no es sólo y simplemente una disposición del ánimo, sino una determinación objetiva y un rasgo esencial de la conciencia humana. ${ }^{43} \mathrm{El}$ carácter escatológico de la esperanza cristiana supera infinitamente las satisfacciones de los que han conseguido o aspiran a conseguir la plenitud social y humana. De otra manera, esta esperanza sería privilegio de los 'afortunados vencedores', quedando todas las víctimas fuera de ella. La esperanza cristiana es eminentemente solidaria porque confía en las promesas de Dios que hace justicia a las víctimas. Tampoco la esperanza cristiana es la simple espera, sino:

"la virtud del camino hacia la libertad, del éxodo hacia la tierra prometida: la esperanza como acción, como compromiso. [...] La esperanza es la virtud de la disconformidad con la realidad, de la rebeldía contra el orden establecido, de la negativa a aceptar el poder del destino sobre la vida

40 Cf. J. J. TAMAYO, Mínimos fundamentales para ser cristianos hoy, en Misión Joven 268 (1999) 21-22.

41 J. B. METZ, La incredulidad como problema teológico, en Concilium 6 (1965) 77.

42 J. B. METZ, La fe, en la historia y la sociedad, 17.

${ }^{43}$ Cf. J. J. TAMAYO, Minimos fundamentales para ser cristianos hoy, 22. 
humana. No se conforma con la fatalidad de la muerte, ni con la negatividad del sufrimiento. Pero el inconformismo de la esperanza no se queda en una actitud más o menos romántica o estética de contento, sino que impulsa a la acción, [...] lleva a asumir la propia responsabilidad en la construcción de un 'mundo nuevo""44.

\section{b.3.- Pasión: caridad}

Por encima de todo ideal de dominio, la identidad cristiana se configura desde el servicio que llega hasta la pasión. El horizonte del sufrimiento rompe todo falso ideal de una autosuficiencia dominadora y toda pretendida inocencia del sujeto burgués. La memoria passionis modela la identidad cristiana de tal manera que siempre se convierte en instancia crítica de cualquier componenda engañosa. La caridad, como elemento constitutivo de la identidad cristiana, no puede ser sólo creída sino practicada ${ }^{45}$.

"El hecho de que en determinadas circunstancias inhumanas no se pueda ser 'ortodoxo' es un síntoma a favor de la humanidad de la fe cristiana. Pero el cristianismo sería inhumano si se limitara a enseñar a soportar las situaciones inhumanas. En tales situaciones no basta consolar, también es preciso curar; son las mismas condiciones de vida las que deben ser transformadas. [...] Y lo escandaloso no es que el cristianismo se presente como religión de los desdichados, como religión de los esclavos, sino algo más grave: que la Iglesia congregue en su seno a los desgraciados $y$ a los espectadores de la desgracia, a muchos que sufren y a muchos que se desentienden del dolor, y que designe al conjunto como la única communio de los fieles" 46 .

La caridad es, como las otras dos, eminentemente socio-teologal. Si el rasgo distintivo del Dios de Jesucristo es el amor, si es su 'definición' más precisa, la respuesta de los creyentes esperanzados en ese Dios no puede ser otra que el amor en toda su extensión, plenitud y radicalidad como fue la respuesta del mismo Jesús, hasta la muerte ${ }^{47}$.

44 J. J. TAMAYO, Minimos fundamentales para ser cristianos hoy, 22.

${ }^{45}$ Quizá en este punto, y sin que sirva de precedente, pudieran estar de acuerdo tanto J. B. Metz como G. Vattimo. Este último afirma que "la caridad no se puede ejercitar en abstracto, sino que debe aplicarse a las situaciones concretas" (G. VATTIMO, Creer que se cree, Paidós, Barcelona 1996, 99), mientras que el discípulo de K. Rahner afirma que nuestro cristianismo burgués está enfermo del veneno dulce de un amor solamente creído cf. J. B. METZ, Más allá de la religión burguesa, 57.

46 J. B. METZ, La fe, en la historia y la sociedad, 152; 155.

47 Cf. J.-J. TAMAYO, Mínimos fundamentales para ser cristianos hoy, 22; Discurso a Diogneto, X, 5-6, en Padres Apostólicos, BAC, Madrid 1950. 
"La fe adulta es [...] donación de sentido absoluto, entroncando así con la capacidad del adulto de 'dar sentido' a su existencia. Pero también crítica y ruptura liberadora de todos aquellos 'sentidos' parciales donde el hombre no se supera bastante a sí mismo. Por otra parte, la fe adulta reclama una apertura radical, como salida hacia arriba, hacia Dios y hacia los hombres. Así radicaliza la fe auténtica la dimensión de apertura constituyente del hombre adulto. También la fe adulta ofrece una oportunidad crítica para su identidad, pero no puede realizarse más que recibiendo la filiación como la misma posibilidad de fraternidad. Por último la misma fe eclesial nos permite vivir la armonía de un amor gozoso y esperanzado que se sabe siempre perdonado y salvado y celebrado en la Iglesia" 48 .

Como resumen de lo dicho, podemos remitirnos a la recomendación que San Agustín dirige a Deogracias en su tarea como catequista: "Por consiguiente, teniendo presente que la caridad debe ser el fin de todo cuanto digas, explica cuanto expliques de modo que la persona a la que te diriges, al escucharte crea, creyendo espere y esperando ame" 49 .

\section{I.4.- La conversión como origen de la identidad cristiana}

Cualquiera puede dar siempre algo más de si, ya que desde el principio nadie es todavía lo que puede llegar a ser como persona. La apertura consciente a la vida que gratuitamente se ha recibido es la condición necesaria para que la persona se abra a horizontes más densos de humanidad. Por el contrario, también es posible ir deteriorando la herencia que hemos recibido hasta prácticamente anular todo resquicio de humanidad. Por eso, la tarea y el reto de orientarnos hacia un mejor y más concreto sentido existencial es un reto ineludible para cualquier ser humano. Renunciar a lo que nos deshumaniza, o deshumaniza a los demás, y embarcarnos en el proceso de un segundo nacimiento para asumir lo que podemos llegar a ser es la tarea más importante de cualquier persona ${ }^{50}$. Este imperativo de todo ser humano, en cristiano se llama 'conversión'. La conversión, como categoría fundamental y fundante de la identidad cristiana, va más allá y es previa a un cambio moral 51 .

48 A. BRAVO, Adultos y fe adulta, en Teología y Catequesis 2 (1982) 187.

49 SAN AGUSTÍN, La catequesis de los principiantes, IV, 8. (=Obras Completas XXXIX) BAC, Madrid 1988

50 Cf. F. HERRÁEZ, Conversión, en C. Floristán - J. J. Tamayo (eds.) Conceptos fundamentales del cristianismo, Trotta, Madrid 1993, 243.

51 La conversión debe ser entendida "como tarea decisiva de la pastoral individual. Una razón de esto, pero no la única, está en que la libertad, como irrepetible autorrealiza 
Por eso, los relatos de conversión son mucho más que la ilustración de una identidad; son su causa. La conversión al Dios de Jesucristo supone revisar "las aspiraciones y los intereses inmediatos centrados en nosotros mismos" 52 . Por eso, la conversión a Jesucristo es un cambio radical en el deseo que orienta toda la vida del creyente. La iniciación -entendida como 'proceso'- es la gran metáfora que habla de un éxodo desde una antigua forma de vida hasta llegar al nuevo nacimiento de la persona según Cristo Jesús. Cuestionar la propia vida es el primer paso para poder replantearla y buscar otra dirección. La conversión religiosa cristiana "consiste en acoger las iniciativas de la bondad de Dios manifestada en Jesucristo, abandonando aquellas actitudes y realidades que, según él, no construyen el verdadero reinado de Dios, para introducirnos a nosotros mismos y al conjunto de la realidad en lo que creacionalmente estamos llamados a ser" 53 .

Los criterios que definen la identidad cristiana hay que buscarlos en la autorrevelación de Dios, que siempre nos precede de forma absolutamente gratuita, y en la respuesta creyente de la persona en comunidad 54 . La persona que -como respuesta de adhesión libre a la gracia del Padre, ofrecida en Jesucristo por medio de su Espíritu-se embarca en el proceso de la iniciación lo hace porque quiere responder a un 'deseo' que afecta a toda su persona. La respuesta a un 'auténtico deseo' sólo es posible realizarla por medio de rupturas y separaciones. La primera etapa de toda iniciación consiste, como ya hemos señalado, en la experiencia de separación. Se experimenta como ruptura con la vida previa. Consiste en separar a los candidatos de las posiciones estructurales que ocupaban hasta entonces. El objetivo de esta separación es

ción histórica del hombre por la que éste fija definitivamente su suerte ante Dios, implica una opción fundamental; opción que el hombre, dada su naturaleza esencialmente reflexiva e histórica, debería realizar con el máximo grado posible de reflexión explícita. De ahí que la conversión no sea tanto (ni siempre) apartamiento de determinados pecados particulares del pasado, cuanto la aceptación decidida y radical, radicalmente consciente, personal y singular, de la existencia cristiana, la cual implica una experiencia real de la libertad, de la decisión por el destino externamente definitivo, y de la gracia (cf. p. ej. Gál 3,5). Y eso sobre todo porque en una sociedad de extremo pluralismo ideológico y anticristiana, el cristianismo del individuo, sin apoyo del medio, no puede subsistir a la larga sin pareja conversión, es decir, sin la personal decisión fundamental por la fe y la vida cristiana." K. RAHNER, Conversión, en Sacramentum Mundi I, Herder, Barcelona 1972, 981.

52 J. B. METZ, La fe, en la historia y la sociedad, 66. Para un buen resumen de la conversión cf. EQUIPO DE CATEQUETAS DE EUSKAL-HERRIA, Fe y conversión, en Nuevo diccionario de catequética I, San Pablo, Madrid 1990, 960-971.

53 F. HERRÁEZ, Conversión, 244.

54 Cf. A. KAVANAGH, Los acontecimientos del ciclo vital. Los ritos civiles y el Cristianismo, en Concilium 132 (1978) 176; A. KAVANAGH, Initiation: Baptism and Confirmation, en Worship 46 (1972) 265. 
arrancar al iniciando "de los valores, normas, sentimientos y técnicas asociadas con dichas posiciones" y despojarle "de sus anteriores hábitos de pensamiento, sentimiento y acción" 55 . Todo lo que anteriormente había configurado la existencia -pensamiento, afectividad y acción- es puesto en cuestión por la separación. La conversión es el nombre cristiano de esta separación preliminar. Sólo desde la conversión a Jesucristo se puede empezar a hablar del inicio de la identidad cristiana. Todo lo demás será desarrollo, profundización y afianzamiento de ese acontecimiento nuclear que está en el origen del cristiano como discípulo. La separación iniciática como ruptura se puede experimentar en la iniciación cristiana de diferentes maneras, pero a lo que siempre ha de remitir es a la experiencia radical de conversión, pues ella es el origen de la identidad cristiana.

"La conversión misma es experimentada como don de la gracia (como recibir la conversión) y como radical decisión fundamental que afecta a la existencia entera del hombre, un cuando se realice en una particular decisión concreta de la vida diaria; ella es fe, como un concreto quedar afectado por la llamada que se me dirige singularmente a 'mí', y como aceptación obediente de su 'contenido'. La conversión es esperanza, como un confiarse al camino inesperado y no fijable hacia el futuro abierto e imprevisible en que viene Dios; es aversión o apartamiento (hecho libremente y, sin embargo, sentido como don) de la vida pasada, con la tarea de la 'expulsión', por la que se reprime la pecaminosidad de la vida anterior; es amor al prójimo, porque sólo en unidad con éste puede amarse de veras a Dios, $\mathrm{y}$, sin él, no se tiene conciencia, ni aun en el centro de la existencia, de quién sea Dios [...]"56

La conversión se experimenta como ruptura y separación de los intereses inmediatos para "centrarse en lo esencial" ${ }^{7}$. Esas rupturas son tanto más necesarias y radicales, cuanto que los objetos a los que se renuncia difieren del objetivo a conseguir. La ruptura con las ideas, sentimientos y caprichos que han configurado al individuo hasta el momento es necesaria ${ }^{58}$ si se

55 V. TURNER, La selva de los simbolos. Aspectos del Ritual ndembu, Siglo XXI, Madrid $1990^{2}, 117$.

56 K. RAHNER, Conversión, 979-980.

57 J. DRAVET, El noviciado, iniciación a la vida religiosa, en Vida Religiosa 75 (1993) 388.

58 En la actualidad se tiene la impresión de que los sentimientos sólo son válidos si son espontáneos. Lo que se pierde de vista, en esta concepción, es que se desconecta el mundo afectivo del intelectual y del moral o ético. "[...] la iniciación se dirige al 'corazón', enseña a dominar los sentimientos para afrontar la 'prueba' y todas las reacciones emotivas. ¿Hasta qué punto nuestra iniciación cristiana toma en consideración esta realidad?" A. LÓPEZ CALVO, La iniciación cristiana: una problemática actual, 11-12. 
quiere ser iniciado como persona en una tradición religiosa como la cristiana, una tradición histórica que se remonta a Jesucristo, modelo de la iniciación cristiana ${ }^{59}$. En los evangelios -que no son biografías de un personaje mítico o histórico, sino elaboraciones catequético-kerigmáticas de la comunidad creyente- Jesús es presentado, entre otros títulos, como Maestro y Camino que invita al seguimiento para llegar al Padre. Este Camino es ofrecido a todas las personas, de cualquier tiempo y lugar, a raíz del acontecimiento pascual por medio de la comunidad cristiana -Cuerpo de Cristo, en lenguaje paulino- vivificada por medio del Espíritu. Desde este enfoque, la historia como anécdota queda trascendida y participa del tiempo y espacio sagrado de Dios sin caer en el mito (entendido éste en su sentido más peyorativo).

La etapa liminar, en un segundo momento, aparece como un desierto o exilio simbólico donde hay que re-pensar, re-configurar y re-focalizar lo que hasta ese momento se había mostrado como evidente, invariable y deseable ${ }^{60}$. Se trata de afianzar la primera conversión, de desarrollar la nueva vida que sea percibida por el sujeto como más deseable para poder trascender los rasgos de la identidad previa. El catecumenado no puede ser otra cosa más que la iniciación a la vida cristiana para adquirir la identidad propia del creyente en Jesucristo. Como iniciación que es, el catecumenado toca todas las dimensiones de la vida del catecúmeno (intelectual, afectiva, moral, social...) para re-modelarlas según Cristo (cf. Rm 15,5-6; Flp 2,1-5;3,3-21; 1 P 3,8-16). El proceso de iniciación cristiana está marcado, como veremos, por una serie de rupturas y adhesiones que no son más que otras tantas formas de apuntar a lo que bíblico-teológicamente llamamos epistrépho ${ }^{61}$ o metanoia ${ }^{62}$ y que aparece en forma de relatos de vocación y conversión ${ }^{63}$.

59 "The effect of ritual, according to Margaret Mead, is to provide a continuity with the past and to provide a shared emotional experience of God." (U.T. HOLMES, Liminality and liturgy, en Worship 47 (1973) 388.

60 Según algunos pensadores, vivimos en un universo cultural donde domina la impulsivilidad infantil. Quizá sea éste un síntoma del mundo postmoderno en el que no se difieren los deseos infantiles inmediatos y, por tanto, no se da ni se quiere dar una auténtica iniciación que modele los deseos primarios.

61 Sub en hebreo significa retornar, volver después de haberse ido... En la versión de

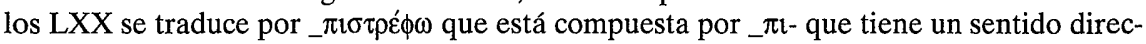
cional que indica "hacia" у $\sigma \tau p \varepsilon ́ \phi \omega$ que significa cambio de dirección, invertir, mudar, volverse, cambiar, dar la vuelta o convertirse; describe un movimiento corporal de retorno orientado por lo general hacia un objetivo o parte. Por tanto,_ $\pi \iota \sigma \tau \rho \varepsilon ́ \phi \omega$ significa un movimiento corporal constatable de retorno. También tiene el significado de un movimiento espiritual o moral. En todos los casos lo que importa es la finalidad o la orientación del sujeto. En lo físico significa dar la vuelta, en lo moral es mirar hacia otro punto, contemplar o adherirse a otra realidad. Es cambiar la dirección de la vida. En los LXX el significado de 
Para conseguir la identidad cristiana, es imprescindible el proceso de iniciación que comienza con la primera conversión a Jesucristo ${ }^{64}$. Identidad, iniciación y conversión cristiana son esencialmente soteriológicas y por tanto han de partir de un enfoque realista de la propia autolimitación. En definitiva, previo a todo proceso de conversión a Jesucristo, la persona ha de percibir o ha de ser iniciada -como dice K. Rahner- "de forma mistagógica, en el reconocimiento de su situación de culpa", no para ser oprimida con una ideología culpabilizadora, como ha sucedido durante tantos siglos, sino para desenmascarar todo mecanismo que disculpa y toda ilusión de inocencia, como nuevo opio del pueblo, y poder ser alcanzados por la auténtica salvación ${ }^{65}$.

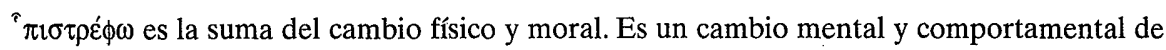
la vida que tiene dos aspectos: uno negativo en cuanto 'dejar' y otro positivo 'ir hacia'. Por eso la conversión es un proceso, porque la persona es un ser enraizado, es un ser histórico. Des-enraizarse supone un dolor y un proceso. Si no asumimos nuestra historicidad, la conversión no será un proceso $\mathrm{y}$, por tanto, no será conversión.

62 Naham en hebreo significa arrepentirse y lleva consigo tener pesar por algo y, por ello, lleva hacia un cambio. En la versión de los LXX se traduce por _ $\mu \varepsilon \tau \alpha$ vor $\alpha$. La partícula $\mu \varepsilon \tau \alpha$ - indica cambio en el contenido del verbo y votev significa pensar, conocimiento profundo, sentimiento, decisión (está muy cerca de kardía que es el núcleo de la persona).

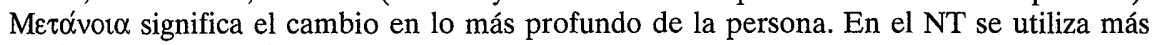

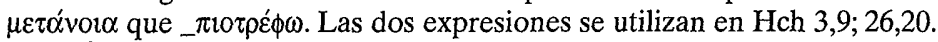

63 La acción pastoral de la Iglesia ha de estar abierta a ofrecer sus cauces de conversión a todo ser humano que estuviera entregado a la tarea de alumbrarse como persona a pesar de que pudiera descubrir que no está interesada en ser creyente en Jesucristo. La entrada en el catecumenado debe exigir un interés en ser persona de manera seria y radical. El catecumenado debe ayudar a afrontar el reto de ser persona. Si esto lo consigue hacer la persona desde los símbolos y persona de Cristo, podrá continuar adelante el proceso de iniciación. Pero la Iglesia, 'Maestra en humanidad', ha de ofrecer el catecumenado a todos los que tengan interés en convertirse plenamente en personas. "Dondequiera se desprende uno de sí mismo ('se niega a sí mismo'), ama desinteresadamente al prójimo, acepta confiadamente su propia existencia junto con la imposibilidad de comprenderla y regirla plenamente, y la acepta como llena de sentido en medio de su carácter incomprensible, sin querer determinar por sí mismo este sentido último ni disponer del mismo, dondequiera uno logra renunciar a los ídolos de su angustia y hambre de vida, ahí se acepta y experimenta el reino de Dios, a Dios mismo (como última razón de tal acción), aun cuando se haga de manera totalmente irrefleja y, por eso, la conversión sea 'implícita' y 'anónima' y en ciertas circunstancias, no se comprenda expresamente a Cristo como palabra definitiva de Dios al hombre (aunque sí se le alcance 'en espíritu').” K. RAHNER, Conversión, 978-979.

64 Cf. J. SASTRE, Algunas claves para una pastoral renovada del sacramento de la confirmación, 66-67. Para la relación entre iniciación e identidad cristiana cf. M. GELABERT, Aspectos teológicos de la iniciación cristiana, en Teología y Catequesis 72 (1999) 55-59.

65 Cf. J. B. METZ, La fe; en la historia y la sociedad, 139. 


\begin{tabular}{|l|l|l|l|l|}
\hline \multirow{2}{*}{ ÁMBITOS } & \multirow{2}{*}{ PERSONA } & \multicolumn{3}{|c|}{ ETAPAS DE LA INICIACIÓN } \\
\cline { 3 - 5 } & & \multicolumn{1}{|c|}{ SEPARACIÓN } & \multicolumn{1}{|c|}{ MARGEN } & AGREGACIÓN \\
\hline intelectual & pensar & ideas adquiridas & re-pensar lo evidente & nuevas ideas \\
\hline $\begin{array}{l}\text { alectividad } \\
\text { motivación } \\
\text { de la acción }\end{array}$ & sentir & sentimientos 'salvajes' & re-configurar el 'corazón' & sentimientos \\
\hline
\end{tabular}

A pesar de que, en la actualidad, la identidad cristiana está sometida tremendos procesos de erosión, todavía las comunidades cristianas locales siguen actuando como si nada estuviera pasando. El peso de la 'civitas christiana' sigue inspirando praxis pastorales inadecuadas al momento presente66: se sigue considerando la fe como algo que se hereda por el mero hecho de pertenecer a un ámbito social con vestigios cristianos, la práctica religiosa se va reduciendo a las 'cuatro estaciones', la necesidad de la acción misionera no se asume como una de las acciones evangelizadoras prioritarias, la catequesis se sigue reduciendo a momentos puntuales sin ofertas procesuales para la iniciación, la acción pastoral suele reducirse a la conservación de un cristianismo individual, la ausencia de comunidades parroquiales vivas desplaza la función iniciática de la Iglesia hacia movimientos con particularidades muy definidas...

Con Álvaro Ginel y Antonio Cañizares podemos afirmar:

\begin{tabular}{|c|c|}
\hline A. Ginel67 & A. Cañizares 68 \\
\hline $\begin{array}{l}\text { "La tradición cristiana ha mantenido } \\
\text { siempre que la fe no es un hecho de la } \\
\text { naturaleza. No se adquiere la fe por el } \\
\text { hecho de existir; creer es admitir que } \\
\text { ocurre en mi existencia un aconteci- }\end{array}$ & $\begin{array}{l}\text { "La tradición cristiana ha manteni- } \\
\text { do siempre que la fe no es un hecho de } \\
\text { 'naturaleza'. No se adquiere la fe por el } \\
\text { hecho de existir; creer es admitir que en }\end{array}$ \\
\hline
\end{tabular}

66 Cf. V. Ma PEDrosA, Causas de la escasez de grupos de catequesis de adultos, en Sinite 106 (1994) 330-332.

67 A. GINEL VIELVA, La iniciación cristiana como lugar especial de la formación del lenguaje religioso, en Teología y Catequesis 4 (1982) 514-515.

68 A. CAÑIZARES LLOVERA, Los sacramentos de iniciación cristiana, en Teología y Catequesis 28 (1988) 632. 


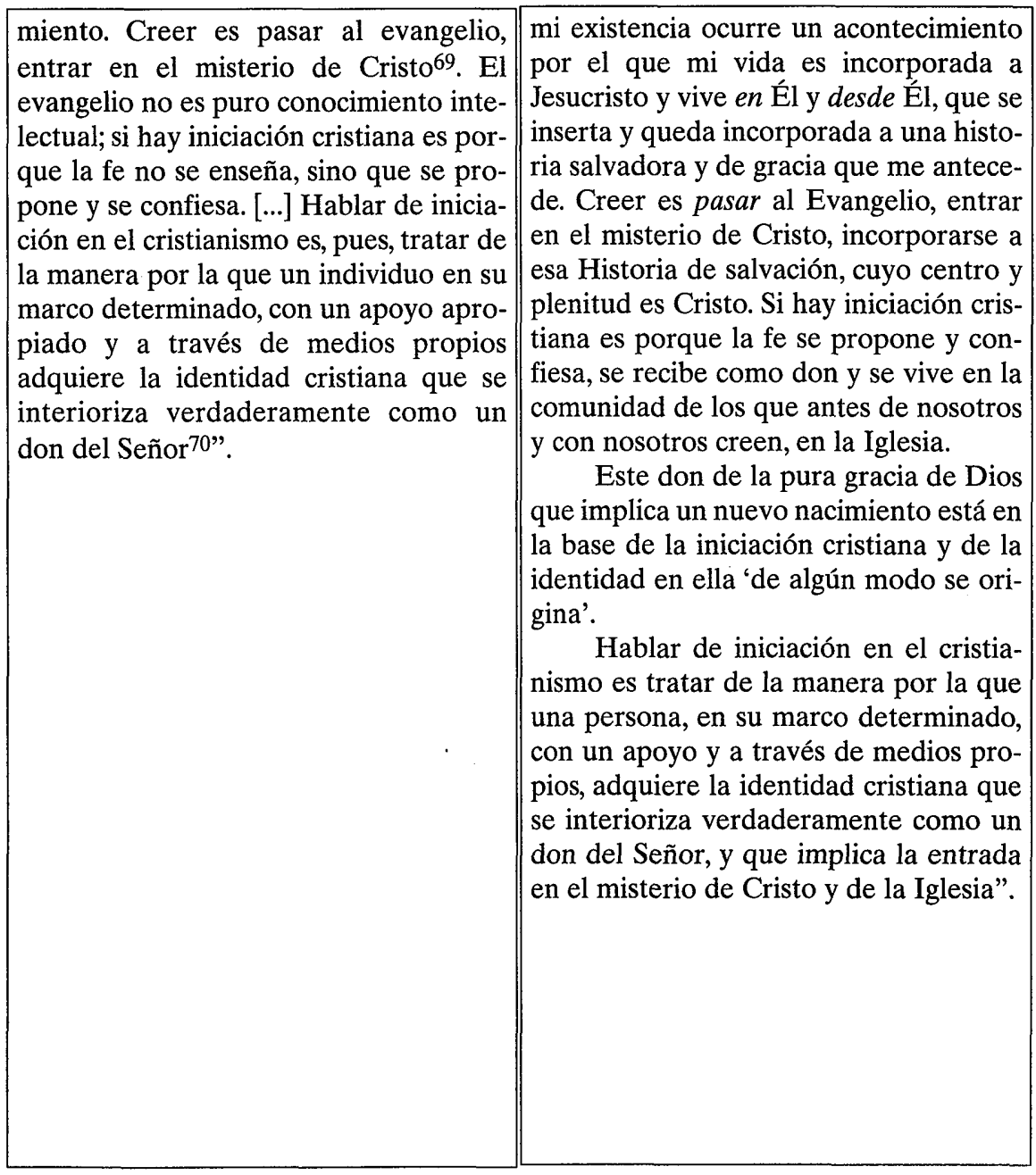

MANUEl BerJón MARTíneZ, osa

Iquitos (Perú )

69 Está citando a H. Bourgeois y a P.-M. Gy.

70 Vuelve a citar a H. Bourgeois. 